\title{
SAKHAROV E OS MÉtodos PARA PESQUISA dA FORMAÇÃO DE CONCEITOS
}

\author{
Gisele Toassa $^{I}{ }^{\star}$; Achilles Delari Júnior ${ }^{I I}$ \\ ${ }^{I}$ Universidade Federal de Goiás, Goiânia, GO, Brasil; \\ ${ }^{I I}$ Universidade Livre da Vila Operária, Umuarama, PR, Brasil
}

Resumo

Este texto apresenta e estuda a primeira tradução para a língua portuguesa de "Sobre métodos para pesquisa de conceitos" (1928), de Sakharov, texto clássico da psicologia histórico-cultural. Em quatro partes, esclarecemos: as opções de tradução realizadas e as relações entre o autor e seu tempo; a discussão sobre métodos de pesquisa de conceitos/talento intelectual, envolvendo análise do objeto, material e procedimentos de investigação de Sakharov em relação com a obra vigotskiana. Debatemos também as críticas, replicações e repercussões do método funcional da dupla estimulação (ou método de Sakharov), apresentado na tradução.

Palavras-chave: método funcional da dupla estimulação; formação de conceitos; método de Sakharov; psicologia histórico-cultural; Leonid Solomonovich Sakharov (1900-1928).

\section{SAKHAROV AND THE METHODS FOR INVESTIGATING CONCEPTS' FORMATION}

\begin{abstract}
This paper presents and studies the first translation to Portuguese of "Methods for investigating concepts" (1928), by LS Sakharov, classic text of cultural-historical psychology. The article was organized in four parts, explaining: translation problems; the relationship between the author and his time; discussion of methods for investigating concepts/giftedness; the object, material and investigation procedures developed by Sakharov in relation with Vygotsky's work. We also discuss the criticism, replication, and impact of the functional method of double stimulation (or method of Sakharov), presented in the translation.

Keywords: functional method of double stimulation; concept formation; method of Sakharov; cultural-historical psychology; Leonid Solomonovich Sakharov (1900-1928).

\footnotetext{
‡Endereço para correspondência: Universidade Federal de Goiás, Faculdade de Educação. R. 235, s/n - Setor Leste Universitário. 74605-050 - Goiania, GO - Brasil - Caixa-postal: 050011010. E-mail: gtoassa@gmail.com, achilles_delari@hotmail.com.
} 


\section{O AUTOR E SEU TEMPO}

Yasnitsky $(2009$, p. 52) observa que o estudo experimental de Sakharov terminou, mais provavelmente, no verão de 1927. Segundo Vigotski (2001[1934], p. 167), o pesquisador não chegou a completá-lo:

$\mathrm{Na}$ série de investigações do processo de formação de conceitos iniciada em nosso laboratório por Sákharov e desenvolvida e completada por nós e por nossos colaboradores U.V. Kotiélova e E.I. Pachkóvskaia, mais de trezentas pessoas foram estudadas, entre elas crianças, adolescentes e adultos, inclusive alguns com distúrbios patológicos das atividades intelectuais e de linguagem.

Concebido sob demanda do laboratório com o qual colaborava e sob influência de Vigotski (SAKHAROV, 2013) e publicado pela primeira vez no periódico Psikhologija, 3, 3-33, O metodakh issledovaniya ponyatii ("Sobre métodos para pesquisa de conceitos"), conforme van der Veer (in SAKHAROV, 1994), constituiu-se em artigo resultante de comunicação na Conferência Pedológica de Moscou em 01 de janeiro de 1928. A mais famosa descrição do "método de Sakharov", aplicação do "método funcional de estimulação dupla" (funktsionalsnaya metodika dvoinoi stimulyatsii) ${ }^{1}$ está no livro Michlênie i riétch, de Vigotski (texto integral em português: VIGOTSKI, 2001[1934]). Mas o texto que ora comentamos é mais pormenorizado no que se refere à descrição da técnica experimental e das mudanças imprimidas por Sakharov ao método de Ach, em diálogo com a tradição alemã para o estudo dos conceitos. Segundo van der Veer (SAKHAROV, 2013,p. 722, nota 20), os resultados principais dessa investigação foram apresentados por Vigotski no Primeiro Congresso para o Estudo do Comportamento Humano, em Leningrado, Janeiro de 1930 (Seção sobre Psicologia, Reflexologia e Fisiologia do Sistema Nervoso) sob o título: "Pesquisa experimental de processos superiores de comportamento".

Sob a chefia de K.N. Kornílov, Leonid Solomonovich Sakharov (19001928) trabalhou com Vigotski no Instituto de Psicologia Experimental, em Moscou, na condição de colaborador externo (in SAKHAROV, 2006, nota 18). Sua única outra publicação enfoca métodos (alemães) de investigação da formação de conceitos. ${ }^{2}$ Em 10 de maio de 1928, pouco tempo depois da famosa comunicação cujo texto ora apresentamos, Sakharov suicidou-se (VEER; VALSINER, 2001, p. 283), sendo o trabalho submetido ao Psikhologija em 12 de Outubro de 1929 (SAKHAROV, 2006).

Foi uma época crepuscular para a revolução cultural que se seguiu à revolução política de 1917, nela também se suicidaram os poetas Maiakóvski , em 1930, e Iessenin, em 1925. Em reflexão sobre a brevidade da vida de seus contemporâneos, Jakobson (2006[1930], p. 36; 40) observa que a alma de Maiakóvski cultivava a dor extraordinária da sua geração frente ao estreitamento das vivências possíveis; o desgaste prematuro de estratos sociais (JAKOBSON, 2006[1930], p. 52) que se lançavam ao futuro de corpo e alma, quebrando o elo dos tempos em 
uma aposta heroica - sem chance de retorno -, em uma nova sociedade. Lamenta o autor: "Tínhamos apenas cantos apaixonantes sobre o futuro e, de repente, esses cantos, frutos da dinâmica do presente, transformaram-se em fatos da história literária" (JAKOBSON, 2006[1930], p. 53). Em um processo criativo liderado por Vigotski (SAKHAROV, 2013, p. 715), Sakharov "rima" na ciência com os suicidados da poesia, ao forjar seu próprio processo de estudo de conceitos a partir do método funcional da dupla estimulação.

\section{Características da Versão RuSSa E da traduÇão americana}

Dado o intervalo de 17 meses entre a morte de Sakharov e a submissão do trabalho, não é possível saber se o material foi revisado pelo autor após sua apresentação pública. Apesar disso, trata-se de um texto extremamente importante, documentando algumas das primeiras iniciativas de estudo experimental dos conceitos como objeto da psicologia que se libertava do cânone wundtiano, por meio de um labor experimental que a se fazia indispensável na afirmação da psicologia como ciência. ${ }^{3} \mathrm{O}$ texto que ora apresentamos foi traduzido do inglês Methods for investigating concepts (Sakharov, 1994) e cotejada com a mais recente versão em russo (SAKHAROV, 2006). ${ }^{4}$

Identificamos as seguintes diferenças entre este original e a tradução americana:

1. Estrutura dos parágrafos;

2. Breve resumo de Korepanova (apenas em russo);

3. Notas: a décima-quinta nota de nossa versão consta apenas na tradução americana. O segundo e o terceiro parágrafos da décima-oitava nota (cuja autoria pode ser de Korepanova) constam apenas em Sakharov (2006) e foram traduzidas diretamente do russo. Tais notas são fundamentais, pois o texto não é de fácil compreensão. Há parágrafos longos e truncados, especialmente na última parte, mas preferimos mantê-los tal como se apresentam na edição em russo que utilizamos. A exposição sobre o "método de Sakharov" seria mais didática com figuras ilustrativas dos estímulos experimentais utilizados, como o faz Vigotski (2001[1934], p. 166) ao tratar do mesmo método.

\section{ObJeto, Material e PROCEDimentos de inVestigaÇÃo}

A ideia de "conceito" não se explicita no texto de Sakharov. Entretanto, as especificidades nela contidas espraiam-se no texto de Vigotski (2001[1934]). A partir dele, deduzimos que o conceito se presta à solução de problemas, transferindo-se entre situações (VIGOTSKI, 2001[1934], p. 167); depreendemos ainda que um conceito não é associação, atenção, juízo, representação, ou a tendência determinante de Ach, conquanto todas essas funções colaborem em sua formação. Seu desenvolvimento dar-se-ia de modo equilibrado, até que o novo emprego funcional da palavra no autodomínio dos processos de pensamento viria a constituir nova ordem qualitativa do pensar, a do "conceito verdadeiro". 
$\mathrm{Na}$ "Pedologia do Adolescente", no Capítulo 10 - de onde se extraíram as seções que formaram o Capítulo 5 de Michlênie i riétch - encontra-se a seguinte definição de Vigotski (2006a[1931], p. 80): "para a psicologia o conceito é um conjunto de atos de juízo, de apercepção, de interpretação e de conhecimento". E que "a estrutura do conceito se manifesta, em nossa opinião, em um sistema de juízos, em um complexo de atos de pensamentos que constituem uma formação integral, única, possuidora de suas próprias leis" (VIGOTSKI, 2006a[1931], p. 82).

Correlato intelectual do significado, o conceito é uma forma de generalização. Sua formação é a de uma síntese complexa elaborada em relação com o meio social nos quais se desenvolvem atividades dotadas de objetivo. Afirma Vigotski (2001[1934], p. 367):

Como mostra a investigação, a medida de generalidade é o momento primeiro e fundamental em qualquer funcionamento de qualquer conceito, assim como no vivenciamento [perejivanie - A.D.Jr.] do conceito, como se pode ver pela análise fenomenológica. Quando nos mencionam algum conceito, por exemplo, 'mamífero', nós o vivenciamos [perejivaem - A.D.Jr.] da seguinte maneira: fomos colocados em um determinado ponto da rede de linhas de latitude e longitude, ocupamos uma posição para o nosso pensamento, recebemos o ponto inicial de orientação, experimentamos a disposição de nos movimentarmos em qualquer direção a partir desse ponto. Isto se manifesta no fato de que qualquer conceito que surge isoladamente na consciência forma uma espécie de grupo de prontidões.

Segundo van der Veer e Valsiner (2001, p. 284), Vigotski e Sakharov acreditavam na necessidade da introdução simultânea de objetos e palavras no estudo dos conceitos. Na tradução, é evidente a grande influência de Ach; quatro pressupostos do método de Sakharov para o estudo de conceitos são originários do famoso estudo de Ach: Über die Begriffsbildung. ${ }^{5}$

1. Estudo do desenvolvimento dos conceitos, de sua formação (obrazovanie), e não de seus produtos (como conceitos já prontos);

2. Caráter sintético-desenvolvimentista, ${ }^{6}$ estudando-se a atribuição de sentido às palavras; a sua transformação em símbolos;

3. Aquisição de um papel funcional pelos conceitos em formação, tal como os instrumentos nas experiências de Köhler com chimpanzés;

4. Os conceitos não são abordados como estruturas fechadas, autossuficientes, ou abstraídas da função a que servem nos processos mentais.

Para além dos métodos das definições e da abstração, criticados no texto, Sakharov (2013) atribui a Ach o uso de palavras experimentais que só podem adquirir sentido no decorrer do curso do experimento. Tem-se como pressuposto que palavras ou características sensíveis a serem abstraídas sem conexão 
interna não são suficientes para a formação de conceitos: enquanto o excesso de palavras fora o calcanhar de Aquiles do método das definições, sua ausência comprometera o da abstração. Tal como no método de Ach, a tarefa do método de Sakharov é localizar peças, que se apresentam em uma "dupla" dimensão, ou seja, como objetos dotados de certas propriedades físicas e significantes passíveis de atribuição de sentido.

O avanço não foi pequeno: com ele, transcendiam-se as abordagens nas quais a palavra era apenas um estímulo entre estímulos, desvinculada de sua condição de relação social concreta - crítica teórica que já se elaborava em Vigotski desde 1925, ainda que o próprio Vigotski apontasse mais tarde que o estudo dos "conceitos artificiais" tinha o limite de lidar com palavras não existentes na realidade social dos sujeitos (ver o capítulo 6 de Vigotski, 2001[1934]).

O nome atribuído ao método experimental de Sakharov é controverso: para muitos, esse seria "o" método funcional da dupla estimulação. Entretanto, uma análise mais cuidadosa de ambos os textos indica que esse foi apenas "um" caso da aplicação do método, cujo fundamento está na apresentação de duas séries de estímulos que adquirem funcionalidade no contexto da apresentação da tarefa experimental:

Para estudar o processo de formação de conceitos, nós nos baseamos na metodologia específica de um estudo experimental que poderíamos chamar de método funcional de dupla estimulação, cuja essência é a seguinte: estudamse o desenvolvimento e a atividade das funções psicológicas superiores com o auxílio de duas séries de estímulos; uma desempenha a função do objeto da atividade do sujeito experimental, a outra, a função dos signos através dos quais essa atividade de [sic] organiza (VIGOTSKI, 2001[1934], p.163-164).

Agora vamos caracterizar oúltimo estágio no desenvolvimento do método para estudo experimental da formação de conceitos em crianças, aquele em que o método de dupla estimulação adquiriu um novo uso sob a influência da ideia de Vigotski sobre o desenvolvimento de formas superiores de comportamento. (SAKHAROV, 2013, p. 715)

A dupla estimulação não nasceu com Vigotski, como se constata no próprio texto de Sakharov: psicólogos da Determinationspsychologie, como Ach, Bacher e Rimat o empregaram, compreendendo que era impossível estudar conceitos à margem dos signos. Para Valsiner (1988), a inspiração estava especialmente em P. Janet e W. Köhler. Segundo Sakharov, todavia, não se compreendeu a função efetiva dos signos na realidade - daí, podemos depreender que os autores se refiram ao método funcional da dupla estimulação, ideia cuja origem está em Vigotski. Ao método de Sakharov, podemos sugerir a denominação de método dos conceitos artificiais ou experimentais, em contraste com outra investigação 
de conceitos exposta em Vigotski (2001[1934]). ${ }^{7}$ Conforme van der Veer e Valsiner, Sakharov considerava o método de busca modificado como "versão especial do método de dupla estimulação, onde a relação gradualmente alterada entre os dois tipos de estímulo - palavras e objetos - é externalizada a um grau extremo" (VIGOTSKI, 2001[1934], p. 287).

No processo de evolução da técnica experimental, o pano de fundo é a criação de uma "psicotécnica" relativa à análise das diferenças individuais (sendo particularmente importante o tema do "talento"), implicada na própria constituição da psicologia como profissão nos anos $1920 .{ }^{8}$ Nessa problemática, a tradução do substantivo odarennost é complicada. Segundo Anton Yasnitsky (comunicação pessoal, 31/03/2013), a palavra estrutura-se em três partes o-dar-ennost, onde o prefixo "o" equivale a "para", com o significado de "vínculo", "união" etc. A raiz "dar" significa "dom", "talento", e a parte final "ennost" é comparável ao gerúndio ("ando", "endo", "indo"). Trata-se de palavra muito próxima do inglês " "giftedness" e o adjetivo odarennyi aproxima-se de "gifted" (brilhante, superdotado, dotado, talentoso).

Como não dispomos do outro texto publicado por Sakharov e o trabalho foi feito sob a regência de Vigotski, julgamos apropriado buscar o sentido da ideia de "talento" em obras deste último. Então, cotejando a "Psicologia Pedagógica" (VIGOTSKI, 2003[1926]) com uma edição em russo (VIGOTSKI, 1991[1926]), a tradução dos termos variando entre "superdotação" e "talento":

Se considerarmos o outro extremo, isto é, as crianças superdotadas, também tropeçaremos na necessidade de modificar alguns métodos e determinadas regras gerais da educação. Tudo isso se manifesta do modo mais grosseiro e simples em algumas formas especiais de talento, como o talento para o desenho, a música ou para a dança, quando só um ensino especial precoce, iniciado a partir da mais tenra idade, pode garantir o desenvolvimento normal das possibilidades latentes na criança. (VIGOTSKI, 2003[1926], p. 284)

Logo na primeira página, Sakharov refere-se à umstvennoi odarennosti, o "talento intelectual", ou "dotação intelectual" como objeto de estudo experimental. Embora a tradução americana traga "intelligence", julgamos o equivalente "inteligência" - impregnado de senso comum - inapropriado para expressar a clara tendência dos textos vigotskianos em contrapor-se à noção de "inteligência geral".

Na seção "Retardo e talento" dos Estudos sobre a história do comportamento (VYGOTSKY; LURIA, 1996[1930], p. 237), os autores afirmam que: "No lugar do termo abstrato e pouco utilizado talento global, propõe-se o novo conceito de toda uma esfera de "capacidades excepcionais' especiais", aparecendo ideia equivalente em Vigotski (2003[1926], p. 237): fazia-se necessária a substituição da ideia de "talentos especiais e abstratos" por "aptidões especiais e concretas". Como Sakharov (2013, p. 711), Vygotsky e Luria (1996[1930]) notam, em quase todos os modernos testes de "talento" a avaliação de funções mentais comple- 
tamente diferentes - desde as inatas até o desenvolvimento de habilidades e a extensão da informação possuída pela pessoa, queixando-se sobre a sobreposição dos dois aspectos. Na contraposição entre "talento inato" e "cultural", Vygotsky e Luria tomaram partido da cultura como criadora de poderosos dispositivos artificiais, permitindo que sujeitos com deficientes capacidades naturais sobrepujassem a escassez de seus recursos "inatos". O próprio Sakharov observa a forte influência das tendências determinantes de Ach (ideia criticada em "O pensamento e seu desenvolvimento na infância", de VIGOTSKI, 1999 [1932]), derivadas da elaboração de nova finalidade/tarefa, em consonância com a teoria da atividade (posteriormente desenvolvida sob a orquestração de A. N. Leontiev).

Os leitores mais exigentes talvez argumentem que a ideia de "talento intelectual" traduzida de odarennost é tão confusa e generalizante como "inteligência". A isso, só podemos responder que este é apenas um dos casos nos quais pode-se identificar uma direção crítica da obra vigotskiana no caminho da superação de ideias de seu tempo, sem que o trabalho de superação tenha se completado. Note-se como o próprio Sakharov procura diferenciar duas formas de talento intelectual (teórica e prática, 2013, p. 712), mas não avança nessa diferenciação.

\section{Críticas e RePercussão}

Aspecto delicado de Vygotsky e Luria (1996[1930]) e Sakharov (2013) é a própria noção de "talento intelectual" e a defesa de sua mensuração à margem da escolarização. Não temos no Brasil muitos relatos históricos sobre a psicologia russa do início dos anos vinte, tampouco acesso às fontes primárias em russo. É provável que na Rússia pós-revolucionária ainda houvesse certa liberdade para o uso de testes psicométricos. O próprio modo pelo qual primeiro exemplifica sua "zona blijaishego razvitiia" no capítulo 6 de Pensamento e linguagem (VYGOSTSKY, 1991[1934]), atesta que só poderia chegar àquelas conclusões sobre as diferentes idades mentais com ajuda ou sem ajuda se tivesse aplicado testes, o que só foi oficialmente interditado com a conhecida "Resolução do dia 4 de julho de 1936", adotada pelo Comitê Central do Partido Comunista da União Soviética (CC do PCR(b)): "Dos erros pedológicos no Narkompros" (ver TEIXEIRA, 2005, traduzindo Golder; e PRESTES, 2010, traduzindo do russo). Tal resolução destaca o que considera serem danos causados

pelo caráter e pela metodologia do trabalho pedológico na escola. A prática dos pedólogos, que ocorria sem nenhuma relação com o pedagogo e as atividades escolares, reduziu-se a experimentos cientificamente falsos e à realização, entre os escolares e seus parentes, de uma infinita quantidade de estudos em forma de questionários e testes sem sentido, nocivos, etc., que há muito foram condenados pelo partido. Esses ditos "estudos" científicos, realizados com um grande número de estudantes e seus pais, eram direcionados, predominantemente, contra aqueles que tinham mau aproveitamento ou aqueles que não se enquadravam no regime escolar. Os métodos dos pedólogos tinham por objetivo provar, do ponto de vista 
"científico" e "biossocial" da pedologia contemporânea, a condicionalidade hereditária e social do mau aproveitamento do estudante ou de alguns defeitos em seu comportamento, como também, encontrar o máximo de influências negativas e de transtornos patológicos no próprio estudante, sua família, parentes, antecedentes e meio social e, com isso, encontrar motivos para a expulsão de estudantes do coletivo escolar normal (COMITE CENTRAL DO PARTIDO COMUNISTA DA URSS, 2010[1936], p. 205-206).

Com os mesmos objetivos agia o amplo sistema de pesquisas sobre o desenvolvimento mental e o talento do estudante. Transferido sem críticas diretamente da pedologia burguesa para o sistema soviético esse sistema representa um desapreço formal em relação aos estudantes e contradiz as tarefas da escola soviética e o bom senso. À criança de 6 ou 7 anos faziam perguntas padronizadas e causais; depois disso definia-se sua chamada idade "pedológica" e o grau de seu talento mental.

"Tudo isso levava a que um número cada vez maior de crianças [fosse] incluído na categoria de retardadas mentais, com deficiências e "difíceis" " (CC do PCR(b), 2010[1936], p. 206).

Vigotski, cujas obras foram proibidas por conta do mesmo decreto, possivelmente não discordasse de algumas de suas determinações, como a de que as crianças com deficiência deveriam passar a estudar em escolas regulares, por exemplo. Contudo, apesar de não negar de forma peremptória o uso de testes, o autor compreendia que deveriam avaliar as capacidades da criança: tanto as envolvidas na realização individual das tarefas propostas pelo investigador, como também as emergentes a partir da relação social com pessoas mais experientes na mesma tarefa.

Um posicionamento mais detalhado do próprio Vigotski sobre essa questão pode ser encontrado no Tomo IV de suas Obras, na seção 3 "O problema da idade e a dinâmica do desenvolvimento" do texto "O problema da idade" (VYGOTSKI, 2006c[1932-1934], p. 251-273). Nessa seção ele se dedica ao que ele mesmo chama de "diagnóstico do desenvolvimento nas diversas idades da criança" (VYGOTSKI, 2006c[1932-1934], p. 265):

Chamamos de diagnóstico do desenvolvimento ao sistema de procedimentos habituais de investigação destinados a determinar o nível real alcançado pela criança em seu desenvolvimento. $\mathrm{O}$ nível real de desenvolvimento se determina pela idade, pelo estádio ou fase na qual se encontra a criança em cada idade. Sabemos que a idade cronológica da criança não pode servir de critério seguro para estabelecer o nível real de seu desenvolvimento. Por isso, a determinação do nível real de desenvolvimento exige sempre uma investigação especial graças à qual pode ser elaborado o diagnóstico do desenvolvimento (VYGOTSKI, 2006c[1932-1934], p. 265). 
Nesse sentido, fica claro que Vigotski não rejeita os processos de avaliação do desenvolvimento real (representando o nível solitário de desempenho do sujeito). Contudo, também é evidente que está tratando do desenvolvimento psíquico como um todo, sem isolar funções particulares de sua dinâmica interfuncional, dicotomizar funções afetivas e cognitivas ou particularizar a ultrageneralizante odarennost, criticado em Vigotski (VYGOSTSKY; LURIA, 1996; VYGOTSKI, 2003). A leitura dos demais textos que falam sobre "as idades" na concepção de Vigotski, confirma isso pela ênfase dada às neoformações como definidoras de uma "idade psicológica" e pela relação entre a emergência delas a cada idade e a correspondente "situação social do desenvolvimento" (ver toda a segunda parte do Tomo IV das Obras: "Problemas da psicologia infantil" - VYGOTSKI, 2006b). Porém, segundo Yasnitsky (comunicação pessoal, 31/03/2013), apenas em 1933 o holismo implicado no conceito de "zona de desenvolvimento imediato" possibilitou a superação das ideias sobre testagem do talento intelectual, criando fundamentos teórico-metodológicos que (deduzimos) privilegiavam a natureza social do desenvolvimento, deixando para trás a velha "dicotomia inato versus aprendido" que a psicologia herdara do discurso filosófico.

A morte precoce de Vigotski e as modificações no seu Círculo de pesquisadores, relacionadas ao recrudescimento do controle estatal sobre a pesquisa científica na União Soviética, ocorreu de modo concomitante à proibição da edição de obras do autor entre 1936 e 1956 e da censura de partes (ou do todo) seus textos até os anos 1980 [...]. ${ }^{10}$ Até hoje a família detém o controle dos arquivos do autor, não os disponibilizando à consulta pública, o que dificulta maiores esclarecimentos sobre os trabalhos experimentais de Vigotski e seu Círculo. Frente a tão graves problemas, não espanta a crítica do cognitivista Jerry Fodor (1972) ou a similar canivetada suíça de Jean Piaget (1995), sobre a "carência" de fundamentação experimental em Vigotski (2001[1934]).

Não obstante, a discussão vigotskiana das relações pensamento-linguagem por meio dos achados experimentais obtidos com o método funcional da dupla estimulação atingiu uma enorme popularidade no Brasil e no mundo, sendo ainda relativamente escassas as iniciativas de replicação. Trabalhos de Hanfmann e Kasanin em 1937 e 1938 (VEER; VALSINER, 2001, p. 306) ressaltaram o valor de seu aspecto qualitativo, introduzindo, contudo, um sistema de pontuação que permitia análise quantitativa dos resultados. Semeonoff e colaboradores tentaram utilizar o método da dupla estimulação como teste de inteligência, sem sucesso. Já a crítica de Harrower (colaboradora de Koffka) sobre as deficiências de padronização do procedimento experimental apenas mostra a preocupação de uma pesquisadora com a busca de medidas confiáveis dos processos psicológicos, enquanto Vigotski e Sakharov interessavam-se pela descrição qualitativa dos processos de desenvolvimento dos conceitos (VEER; VALSINER, 2001). Descrição que deveria ser multilateral, permitindo também a sua explicação.

Recentemente, Paula Towsey (2006) realizou na África do Sul uma replicação do método da dupla estimulação. A autora recupera parte das adaptações publicadas por Hanfmann \& Kasanin (TOWSEY, 2006), buscando um meio-termo entre esse método e o original em uma replicação experimental realizada 
com 60 sujeitos, de meios sociais urbanos e privilegiados. Seus experimentos confirmaram o uso de estratégias de pensamento também presentes em Vigotski (2001[1934]; 1994[1934]), concluindo sua dissertação com o relato de que o método possibilitou-lhe observar o "lado humano" da resolução de problemas, sendo interessantes os diálogos com os sujeitos após a tarefa, sobre o caráter inequivocamente individualizado de seus processos de resolução. Como todos os pesquisadores que aplicaram o método da dupla estimulação, Towsey concordou com o elevado grau de dificuldade da tarefa.

Entretanto, a despeito de sua grande importância no estudo da formação de conceitos, o método de Sakharov é apenas um dentre os métodos da psicologia histórico-cultural. Fato evidente quando analisa uma das fraquezas daquele:

Em realidade, a fraqueza da nossa investigação anterior consiste na ausência de um automovimento dos conceitos, de uma ligação entre as fases do desenvolvimento. Essa falha se deve à própria natureza do experimento que, por sua estrutura, exclui a possibilidade de: a) elucidação dos vínculos de uma fase para outra, e b) revelação das relações de generalidade, uma vez que, pela própria metodologia do experimento, cabe ao sujeito experimental, depois de uma solução incorreta do problema, anular o trabalho realizado, destruir as generalizações antes constituídas e recomeçar o trabalho pelas generalizações dos objetos singulares. Uma vez que os conceitos escolhidos para o experimento estavam no mesmo nível de desenvolvimento que a linguagem autônoma da criança, eles podiam correlacionar-se só horizontalmente, mas não distinguir-se pela longitude. Por isso fomos forçados a dispor as fases como círculos que se distanciam para a frente em um plano, em vez de distribuí-los como uma espiral de círculos por uma série de ascendentes (VIGOTSKI, 2001[1934], p. 370-371).

Apesar das críticas, de ser superestimado no escopo da metodologia histórico-cultural, da escassez de replicações, as três grandes "fases" da formação de conceitos identificadas a partir do emprego do método de Sakharov - "pluralidade não informada e não organizada", "formação de complexos" e "conceitos verdadeiros (ou científicos)" - hoje ocupam um lugar extremamente expressivo no campo da psicologia e da educação. Não se pode afirmar que o método de Sakharov e esses resultados tenham sido negados, mas sim incorporadas em um sistema teórico um tanto mais potente no qual as "estruturas tipificadas de generalização" (síncreses, complexos e conceitos) integram-se com um "sistema de coordenadas" (com latitude [conteúdo concreto]; longitude [grau de generalidade]; e medida de generalidade [cruzamento dos dois primeiros]), além do que a questão é vista como relativa a todo um conjunto de operações mentais variadas que constituem os modos de funcionamento do sistema: juízos, conclusões, com- 
parações (identidade/diferenciação), entre outras que não me lembro agora. Sem falar do interessante problema de como se gera o pensamento original, que supera os simples e redundantes silogismos.

Cabe realizar análise mais detalhada e autocrítica desse lugar, o que inclui a percepção das dificuldades da psicologia histórico-cultural em arraigar-se nos cursos de formação de psicólogos, onde continua a ser explorada de forma majoritariamente superficial e não experimental; a relativa escassez de uma tradição no campo da pedagogia experimental; o desconhecimento com respeito a Sakharov (2013) como determinações prováveis para a carência de tentativas de replicar os experimentos com o método funcional da dupla estimulação, reavaliando sua potencial contemporaneidade. Acreditamos que o presente texto auxilia seus leitores a transcenderem os umbrais de uma psicologia ingênua da formação de conceitos, não obstante a datada tentativa de Sakharov - presente apenas em textos de Vigotski que ele próprio superou em sua trajetória - em buscar a medição do "talento intelectual". Tanto mais, à margem dos processos de escolarização e da compreensão da história política, econômica e social da população brasileira e soviética nos anos 1920.

\section{Agradecimentos}

Agradecemos ao editor René van der Veer, autor das notas presentes em Sakharov (1994), pela cessão dos seus direitos para a presente tradução em língua portuguesa, e a Anton Yasnitsky, por opinar sobre a tradução de odarennost.

\section{Notas}

\footnotetext{
${ }^{1}$ Noutros trechos do texto, Sakharov abrevia para metod dvoinoi stimulyatsii (método da dupla estimulação).

${ }^{2}$ SAKHAROV, L. S. Obrazovanie ponjatij u umstvenno-otstalykhdetej (Referat) ("A formação de conceitos em crianças mentalmente retardadas" (uma sinopse). Voprosy Defektologuii, 2, 1928, p.24-33.

${ }^{3}$ Wundt cindira o campo psicológico em duas diferentes ciências - a psicologia fisiológica (experimental) e a dos povos (descritiva), como expõe Farr (1998).

${ }^{4}$ Michel Vale traduziu o texto para o inglês e publicou na Soviet Psychology, 1990, 28,35-66, Julho/Agosto. Quase todas as notas são do editor René van der Veer.

${ }^{5}$ Ach, N. 1921: Über die Begriffsbildung. Eine experimmentelle Untersuchung. Bamberg: C. C. Büchners Verlag, cujo título pode ser traduzido como: "Sobre a formação de conceitos. Uma investigação experimental". Narziss Ach (1871-1946) foi um psicólogo alemão da Escola de Wurtzburg (junto de Külpe, Bühler e outros, cf. Luria, 2001 (P-L), p.451). Contrário aos associacionistas, elaborou a ideia de que o pensamento, no decorrer da resolução de tarefas, são determinados por uma tendência nela implícita - a tendência determinante (a partir de nota nas Obras Escogidas, II, p.79).

${ }^{6}$ Vemos sintético-genético, no texto de Sakharov (2006) e Vigotski (2001[1934], p. 153).

${ }^{7}$ Note-se, no Capítulo seis de Michlênie i riétch, a referência de Vigotski a pelo menos quatro séries de investigações, uma das quais se refere ao "estudo comparado dos conceitos espontâneos e científicos (também traduzível como acadêmicos)”, por Jozefina Shif (Vigotski, 2001[1934], p. 389).

${ }^{8}$ Vale ressaltar que a ideia de "psicotécnica" não se restringe à elaboração de "técnicas/métodos de pesquisa", mas sim contempla a noção de psicologia aplicada (às organizações, à educação, à medicina, à economia, à estética etc), como se vê em Vigotski (2003[1926], p. 43): "a psicotécnica pedagógica, análoga a outros ramos da psicotécnica e que se dedica à pesquisa psicológica aplicada à educação".
} 
${ }^{9}$ Afirma Sakharov (2013,p. 715) que: "Sob a influência de uma tarefa e das tendências determinantes dela derivadas, processos mentais passam por uma mudança abrupta" .

${ }^{10}$ No Ocidente, após a época de maciça proibição da edição de Vigotski na União Soviética, a primeira obra editada foi Pensamento e linguagem (em 1962, VEER; VALSINER, 2001, p. 304).

\section{REFERÊNCIAS}

ACH, N. Über die Begriffsbildung: eine experimmentelle Untersuchung. Bamberg: C. C. Büchners Verlag, 1921.

COMITÊ CENTRAL DO PARTIDO COMUNISTA DA URSS. Resolução do CC do PCR (b), de 4 de julho de 1936. Sobre as deturpações pedológicas no sistema do Narkompros. 1936. In: PRESTES, Z. Quando não é quase a mesma coisa: análise de traduções de Lev Semionovitch Vigotski no Brasil, repercussões no campo educacional. Tese (Doutorado)_Universidade de Brasília, Brasília, 2010. Anexo 2, p. 205-208.

FARR, R. As raizes da psicologia social moderna. Petrópolis: Vozes, 1998.

FODOR, J. Some reflections on LS Vygotsky's Thought and Language. Cognition, p. 83-95,1972.

JAKOBSON, R. A geração que esbanjou seus poetas (1930). São Paulo: Cosac Naify, 2006.

PRESTES, Z. R. Quando não é quase a mesma coisa: análise de traduções de Lev Semionovitch Vigotski no Brasil - repercussões no campo educacional. 2010. Tese (Doutorado)-Faculdade de Educação da Universidade de Brasília, Brasília, 2010.

SAKHAROV, L. S. Obrazovanie ponjatij u umstvenno-otstalykhdetej (Referat) ("A formação de conceitos em crianças mentalmente retardadas" (uma sinopse). Voprosy Defektologuii, n. 2, p. 24-33, 1928.

SAKHAROV, L. S. Sobre métodos para pesquisa de conceitos. Fractal: Revista de Psicologia, Niterói, v. 25, n. 3, p. 695-724, set./dez. 2013.

SAKHAROV, L. S. Methods for investigating concepts (1930). In: VEER, R. van der; VALSINER, J. (Ed.). The Vygotsky Reader. Oxford, UK: Blackwell, 1994. p. 73-98.

SAKHAROV, L.S. O metodakh issledovaniya ponyatii. Kulturno-istoritcheskaia psikhologuiya // Cultural-HistoricalPsychology. n. 2, p. 32-47, 2006. Disponível em: <http://psyjournals.ru/en/kip/2006/n2/Sakharov.shtml>. Acesso em: 10 jan. 2012 . 
TEIXEIRA, E. Vigotski e o materialismo dialético: uma introdução aos fundamentos filosóficos da psicologia histórico-cultural. Pato Branco, PR: FADEP, 2005.

TOWSEY, P. In search of Vygotsky's blocks: exploring CEV, BIK, MUR, and LAG in South Africa. Md Dissertation. Faculty of The Humanities, University of The Witwatersrand, 2006. Disponível em: <http://wiredspace.wits.ac.za/ handle/10539/5859>. Acesso em: 23 jan. 2013.

VALSINER, J. Developmental psychology in the Soviet Union. Brighton, Sussex: Harvester, 1988.

VEER, R. van der. Notes. In: VEER, R. van der; VALSINER, J. (Ed.). The Vygotsky Reader. Oxford, UK: Blackwell, 1994. p. 26-27.

VEER, R. van der; VALSINER, J. Vygotsky: uma síntese. São Paulo: Loyola/ Unimarco, 2001.

VIGOTSKI, L. S. Pedagoguitcheskaya Psikhológuiya (Psicologia Pedagógica) (1926). Moskva: Pedagoguika, 1991.

VIGOTSKI, L. S. O desenvolvimento psicológico na infância (1932). São Paulo: Martins Fontes, 1999.

VIGOTSKI, L. S. A construção do pensamento e da linguagem (1934). São Paulo: Martins Fontes, 2001.

VIGOTSKI, L. S. Psicologia Pedagógica (1926). Porto Alegre, RS: Artmed, 2003.

VYGOTSKI, L. S. El desarrollo del pensamiento del adolescente y la formación de conceptos (1931). In: . Obras escogidas. 2. ed. Madrid: Visor y Antonio Machado Libros, 2006a. Tomo IV, p. 47-116.

VYGOTSKI, L. S. Obras escogidas (Psicologia Infantil). 2. ed. Madrid: Visor y Antonio Machado Libros, 2006b. Tomo IV.

VYGOTSKI, L.S. El problema de la edad (1932-1934). In: . Obras escogidas. 2. ed. Madrid: Visor y Antonio Machado Libros, 2006c. Tomo IV, p. 251-273.

VYGOTSKY, L.S. Pensamento e linguagem (ANO). São Paulo: Martins Fontes, 1991. 
VYGOTSKY, L.S. Thought in schizophrenia (1934). VALSINER, J. (Ed). The Vygotsky reader. Oxford, UK: Blackwell, 1994. p. 313-326.

VYGOTSKY, L. S; LURIA, A. R. Estudos sobre a história do comportamento: o macaco, o primitivo e a criança (1930). Porto Alegre: Artes Médicas, 1996.

YASNITSKY, A. Vygotsky Circle during the decade of 1931-1941: toward an integrative science of mind, brain, and education. 2009. PhD thesis, University of Toronto, Toronto, 2009.

Recebido em: 22 de abril de 2013 Aceito em: 11 de setembro de 2013 